\title{
Judo as a Work of Art
}

\section{Shorkend D* \\ University of Tel Aviv, Israel}

*Corresponding author: Dr. Daniel Shorkend, University of Tel Aviv, 41 Disraeli, apartment 4, Haifa, Israel, Tel: 00927584075523; Email: dannyshorkend@yahoo.co.uk

\section{Research Article}

Volume 3 Issue 3

Received Date: August 18, 2020

Published Date: September 23, 2020

DOI: $10.23880 /$ phij-16000152

\section{Abstract}

In this brief article i make the argument that the first principles inherent in art, that is its formal components such as line, colour, composition and so on can be viewed as mechanism enabling a deeper aesthetic appreciation of sport. In this particular case the sport looked at is judo. If this thesis is correct, it implies an interdisciplinary field of study traversing art and sport, the humanities and the sciences and over turns the old Cartesian dualism in favour of a more integrated embodied experience.

Keyword: Judo; Aaesthetics; Art; Performance; Interdisciplinary

In this essay, I shall analyse how one may take the basic principles of art or the first principles that inhere in the construction and making of say a painting (dance, music, performance are other possible avenues other than the visual arts, but that would be for another discussion and one equipped with the requisite training in these arts) and show that such an understanding may be applied to the sport of judo. If this is the case, then one might make a similar claim for sports in general. That is, art and sport form parallel and even overlapping ways of knowing, both in terms of the participation thereof and viewing, analysis and critical understanding. While David Best argued that not all sport can be considered aesthetic, I believe this is not necessarily true - that sport is aesthetic whether purposive or not and moreover, that it is a kind of art. I intend to do this with a discussion of judo by showing an overlap with the visual arts. If this is deemed successful, I would argue that a new field of interdisciplinary study awaits that connect art and sport not simply in the theoretical sense but may even have practical applications. The latter point is purely conjectural and in this essay I seek simply to outline an approach that may pave the way toward this in the foreseeable future.

\section{Line}

Works of visual arts (and for the discussion I take painting as the paradigm example) necessarily use line.
Lines may enclose a form, recognisable or not. Lines define boundaries. They construct shapes and lead the eye in a particular way. Lines are two dimensional, but may evoke the three dimensional. They are of a designated width and length, executed at a particular rate with a sense of force, urgency or slowness as the case may be. They express by virtue of the sensitive onlooker an emotive quality and one might say an artist has a signature kind of line, whether it is say a lyrical Matisse, a strong Picasso, a nervous Ben Shan, the urgency of Van Gogh, the precision of Stella and so on and so forth. Lines ordered in a particular way form patterns and designs.

In fact, the use of a particular line, say the profiles of Egyptian figuration, the flatness of the middle Ages, the soft, highly representational line post Renaissance Europe and so on, define the very institutional and ideological context in which the visual arts are made.

How then does line have relevance in a sport such as judo? To do judo and to teach judo, requires an intuitive grasp of what I call "lines of force". When am I off-balance or my opponent for that matter? How can that student be better aligned and in position? Why did that throw look beautiful? I believe that the answer to these questions is not simply anatomical and reduced to scientific-speak.

The "other" solution is that one is responding 


\section{Philosophy International Journal}

aesthetically. That is, when one times a throw, one as it were, sees a particular line running through self and opponent at a certain angle; one intuits where a line ought to go like a soccer player that runs into a good space or a pass that bisects two defenders and reaches his colleague in an on-side position in an ideal region of the field. One can imagine this like seeing the options on a chess board, visually illustrated with lines of possibility. When one sees an ippon - a perfect demonstration of a throw - one responds aesthetically precisely because these lines of force are perfectly symmetrical, poised and in tune. When one demonstrates to a student what movement is required one draws with the students body the direction, movement and force that is akin to lines being created, shifted and mobilised to best effect within the constraints of the game.

\section{Colour}

If the above is somewhat convincing, then surely colour is an exception. What on earth can colour have to do with excellence in a sport such as judo? This is hypothetical, but I propose that if one took the gear of say a soccer team and created a kind of fractal generated program whereby the colours of that team kit somehow visually overran their opponents' colours or kit, then this would positively affect performance. It is a kind of visualisation for success on the sports field. Granted such indulgence, how would that apply to judo. The athlete simply wears either a white or blue gi (judo suit) with a belt (usually black at a high level of the sport). The answer? I am going to make what may appear a rather absurd statement: The successful judo player actually (consciously or not) likes (loves) the colour of her gi, the colour of the mat and the order of the surrounds. If she does not feel that way disposed, performance will be adversely affected.

This may not be that preposterous if one considers visual culture and here I include not only the visual arts, but all manner of society: courthouses and hospitals, political rallies and schools, gardens and dress code, dinners and parties and so on and so forth. In order for one to be disposed favourable in any manner of context an attunement and enjoyment of colour must somehow be included. Sometimes this takes training or just plain familiarity, like a new art form that is at first disliked. Today, we do not bat an eyelid at a Fauvist painting when initially it was shocking. The strong gold and blue of a painting from the Middle Ages would have ignited a sense of royalty and mystery. The pageantry of the Olympics gives it significance and a heightened atmosphere.

Colour affects us. Thus, if one were to consciously ingratiate ourselves with a certain colour code, then that might have a dramatically positive effect on how one performs. Therefore, in judo one must feel something positive to blue and white and the general context - it ought to be attractive.

\section{Composition}

Composition could be defined as the holistic organisation of lines, planes, spaces and colours towards an overall unity. In art, we speak of the eye being led in a certain way given a certain compositional order. We speak of the "unseen" yet tacit geometric construction of a say a painting, in terms of triangles and rectangles, circular motion, $\mathrm{S}-$ shapes and so on.

Given the discussion thus far, one may apply this to judo with the following considerations: A non-verbal bodily understanding of self and opponent in terms of balance, weight, force, direction, etc. is the sum total of the coordination of lines. When one tacitly understands as such, one creates harmony or a compositional unity when executing a particular throw, unhinging ones opponent, destabalizing him and skilfully demonstrating a judo move. This can be analysed mechanically and physiologically, but the key claim of this essay is that this is also an aesthetic impulse and in particular similar to what occurs when one creates a work of art with what is called compositional harmony and the like.

This does not discount the craft of art and the craft of plying a particular sport such as judo. Only that the physical ability is skilful precisely when there is an aesthetic experience. That is, inertia is overcome when there is mobility of line like a harmonised set of sounds or a uplifting display of colour. Or a well-timed skilfully generated judo sequence.

\section{Scale}

A sense of scale contributes to the success of an artwork. Whether a painting is say large or small, the artist must attend to the details within the picture surface with due consideration for the overall size of the surface and the relationship between the elements within it. One often uses the expression: "To size up one's opponent". One needs to have a sense of one's own scale in real terms vis a vis one's opponent. One might even successfully imagine oneself larger or at any rate not dwarfed by the context and certainly not diminished by one's opponent.

Scale is thus both physical and psychological. The sense of power one has as an artist is gained from really feeling and been in touch tangibly with the surface and the relative sizes of things within it. In judo, one must have a sense of proportion - neither too large or too small - and at the same time not believe one's composition is beyond one's ability to fell, that the size is too great. One must, as it were, think through the body of self and opponent, and in a similar sense, articulate 


\section{Philosophy International Journal}

within the scale of the surface various forms of various sizes, in order to both be in control and allow things to be within the painting arena (mat) and activity (performance, fight).

\section{Format}

Related to scale is a feeling, a physical sense of the dimensions and visceral quality of the surface on which one paints or fights. The format ought to invigorate one. In judo, stepping beyond the mat may result in a penalty. In art, one's expression is to be focused within the painting format (canvas, board or whatever), excluding what happens around it. Therefore, a clear sense of a) the dimensions of the arena and b) the actual quality of the arena - how soft is the mat/ the surface on which one paints; what is its' texture; do the colours appeal and from this a sense of what one can do on it, that is to say how can one relate to - and act - most successfully within it. To achieve optimal performance, I conjecture that an appealing surface and context is significant.

\section{Texture}

A famous soccer player once remarked that before he enters the playing field of an important professional match, he takes a bit of the grass on which the play is about to commence and feels it and then smells it, especially when it comes to home matches. In an analogous manner, the judoka needs to feel comfortable in his gi (judo apparel) and feel that the mat will always cushion and feels comforting beneath his feet (now all this need not be overtly conscious, simply intuited and felt). In the similar way that the judoka (judo player) feels happy with his equipment, so the artist thinks through the viscosity of paint, canvas and other extraneous materials, so that he thinks though them just as the judoka player plays via his gi on the fighting arena. The artist (aesthete/athlete) also creates within the surface not simply a flat form but either implies a textured surface regarding his objects painted and/or actually allows the very quality of the paint and other materials to be revealed. So the judoka is one with his apparel and expresses himself through it: in both cases the equipment, however limited is a kind of extension of his body, the very textural reality of material.

\section{Tone}

A sense of light. A sense of darkness. Here the artist uses tone to articulate form and to express the play of light, either realistically or imagined, and in the process is connected to the nuanced effect of natural or imagined light. The athlete too is subconsciously aware - or so I hypothesize - of the light that radiates in the hall arena, that toys with the gi, that attends himself and his opponent. For in that awareness lies a sense of energy, for light is energy - and in the awareness of the shadow, of darker hues, even of black - is a portal to another kind of fighting energy. In the interface between light and dark lies the capacity to initiate, to be active or passive as the situation warrants and to move decisively.

\section{Form}

One might see a judoka hitting his chest or legs or hips just she is about to enter the fighting arena. Is that a kind of making conscious that one is physically alert as a threedimensional form and to awaken a sense of one's weight? This three-dimensional form or mass now feels energised for the task at hand and gives a certain dimension so that one may act optimally. The artist often creates a sense of the three-dimensional on a two-dimensional surface and this act of illusion gives such forms weight and what is often termed realism. But form can also be two-dimensional - a shape that as Rothko once said is a type of living organism. The connection to judo? It may be significant that the athlete senses herself and her surrounds with depth - time, three spatial dimensions and the inner world. Insofar as form is perceived, a sense of the palpably real and beautiful may emerge. The seeming flatness of the mat is rather a cushion; one's opponent is not simply a video game and one's own self is alive within the realm of length, breadth and depth. Similarly, in the arts painting (for example Stella) is as much a form, an object as is sculpture, over and above the centuries old tradition of realism and representational art or the distortions of form in expressionism, pre-abstract, fauvism, cubism and so on.

\section{A Work of Judo or Performance}

One could claim that in art the extrinsic aim to create a work, a particular body, as it were whereas in sport this is not the explicit aim. Furthermore, that art is not agonistic and pragmatic as in the case of sport, where it is not the work or performance perse that is the intrinsic aim, but the tallying of points in a very defined way toward victory.

Now, these assertions may be countered. Is art not also an institution where there is competition, victory being the canonisation within the history and theory of art and honour, not to mention financial gain? As to the first point, a judo player is trying to secure victory in whatever way possible within the rules and is not overly concerned with creating a beautiful form or performance, but simply trying to win within her means. This is not necessarily true for the latter can only be accomplished by a well-co-ordinated manoeuvre, by producing a beautiful act of skill, by performing well.

\section{Gesture}

Jackson Pollock may have undone the tradition of painting with his swirls and drippings or in another sense; 


\section{Philosophy International Journal}

he made it patently clear that the act of mark-making is an active, highly gestural activity. It requires movement. Here it is not simply the hand and wrist that is in motion, but the whole body. This is significant when it is obvious that judo requires the full exercise of the body in specific kinds of movements. Both are creative, responding to inner and outer cues and innervations.

One might even parallel particular kinds of motions in both acts. The hand and wrist is crucial in both cases, but in the more expansive and expressive kinds of painting, one involves the whole body. The hip is crucial in judo supported by the base that is the legs. The back needs to be strong and supply, the arms relaxed and tensed at just the right moments and the neck and head need to lead and propel one in a certain motion. One can imagine Pollock, who said of his large scale works and methods that he felt within the painting, to be a clue that he felt the need to almost dance in and around the painting and I would surmise we may even find a very particular kind of judo movement there. It is interesting that painting as a Fine Art led in some ways to happenings and performance, that is, live action, rather than the intermediary that is the external work of art. The act of painting leading to real live gestures. In the more conservative act of painting (sculpture would probably form an even more robust parallel and convergence), one might still note a certain dexterity of hand and wrist that is somewhat athletic.

\section{Training}

In order to hone an art or a sport requires training in one's craft. Music may aid one's judo to find rhythm. Dance is a mid-point between art and sport. Could it be that crosstraining, that is, doing art for the purposes of improving judo performance is viable and may in fact work? My hypothesis is that this is the case and given the aesthetic overlaps in theoretical space, as it were, the dialectic may also operate on a practical level.

\section{Conclusion}

I take as axiomatic that sports as with art are aesthetic modalities. In this essay, I have argued as such using basic artistic properties within the field of painting and shown how they might apply to judo. In the process, I hope to invite the argument that judo is a kind of art. My task then is to show how art-related aesthetics can be useful to explain and develop sport theory in a new way. "New" in the sense that an affinity between the two is described and argued for, although this has been somewhat developed in the recent past in the 1970s and 1980s triggered by Reid LA [1], Kupfer J [2], Best D [3-5], Wertz SK [6] and Cordner [7]. My intention or contribution is, unlike these write, not a concern with the question whether sport is art, but simply developing $a$ theoretical framework that motivates the theoretical overlap between art-related aesthetics and sport. Such an overlap - whether aesthetic, extra-aesthetic - may enhance our experience (in art and in sport as in life). This implies a "third concept" (a trans disciplinary field), which would explain the endless oscillation, but one which is potentially dialectical, so that in that process there is a beautiful "wrestling", even a "wrestling" with the concept of "beauty" itself.

The paradigm shift in philosophical thinking which Shusterman [8] neatly describes as a "vision of an essentially situated, relational, and symbiotic self rather than the traditional concept of an autonomous self-grounded in an individual, monadic, indestructible and unchanging soul" implies that there is always some aspect of the body (or rather somo - the living body) in the understanding of persons and aspects of world. The dominant Platonic-Christian-Cartesian tradition is thus challenged by the fact that we think and act through our bodies so that in Shusterman's (2008:19) words: "if the body is our primordial instrument in grasping the world, then we can learn more of the world by improving the conditions and use of this instrument". In view of this it seems natural to turn philosophical attention on sport, a bodily activity and in particular judo toward demonstrating its aesthetic and even artistic dimensions.

\section{References}

1. Reid LA (1970) Sport, the aesthetic and art. British Journal of Educational Studies 18(3): 245-258.

2. Kupfer J (1983) Experience as art: aesthetics in everyday life. Albany: State University of New York Press.

3. Best D (1978) Philosophy and human movement. London: Allen \& Unwin.

4. Best D (1979) Art and sport. Journal of Aesthetic Education 14(2): 69-80.

5. Best D (1986) Sport is not art: professor Wertz's aunt Sally. Journal of Aesthetic Education 20(2): 95-98.

6. Wertz SK (1993) A response to Best on art and sport. Journal of Aesthetic Education 8(4): 105-108.

7. Cordner C (1988) Differences between sport and art. Journal of the Philosophy of sport 15(1): 31-47.

8. Shusterman R (2008) Body consciousness: a philosophy of mindfulness and somaesthetics. New York: Cambridge University Press.

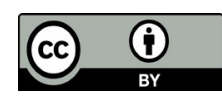

